\title{
Health Monitoring of Structures Using Modern Tools
}

\author{
P. B. R. Dissanayake
}

\begin{abstract}
The health monitoring of old structures is an essential part in Civil Engineering. In Sri Lanka, there are a variety of old structures such as stupas, ancient monuments, buildings, bridges, and dams. Some of these structures (e.g. Stupas) are more than 2000 years old and are national treasures. Other old structures such as buildings, bridges, etc are nearly 100 years old and most of them dates backs to British colonial period. Interestingly, these are still used in social life. Hence, appraisal of these structures considering future existence and use is important at the national level. But this is often difficult owing to the lack of defined methods. This paper describes how health monitoring can be done using analytical and experimental considerations. In this context, three cases studies; namely, an old building, an old reservoir and an old bridge, in relation to load carrying capacity and displacements are used as illustrative examples.
\end{abstract}

Keywords: Experimental methods, Analytical methods, Health monitoring, Old structures

\section{Introduction}

In today's rapidly changing world, the quality of human life and economic progress of a country depend on the quantity, quality and efficiency of its infrastructures system [1] Everywhere around the world, there is a need for significant investment to repair civil infrastructures, which are deteriorating under heavy use, severe exposure conditions, and age $[1,2]$. Economic depressions that happened in mid 1990's in the world have in fact caused more research expenditure on innovative health monitoring techniques that will enable optimum maintenance of structures.

Most of civil engineering structures have three phases in their service life; design, construction and maintenance. With our knowledge in structural engineering and present development of technology, design and construction of structures are well defined tasks at present. It is a matter of following well-described codes and guidelines and execution with desirable construction techniques. In contrast, the maintenance stage of a structure is the least attended stage most of the time. During the maintenance stage, continuos health monitoring of structures is an essential part. That will reduce the life cycle cost of the structure and enhance the performance of the structure.

There are number of different types of health monitoring used for varying purposes. Some are comprehensive and some have only an incidental structural interest. It is often involved with the available resources. Since there are many types of structures, the process of health monitoring is different depending on the type of structure. Hence, health monitoring as a first job, may become rather difficult to even a well qualified engineer.

The first decision that an investigator has to make is what to investigate and how to do it in order to achieve the purposes. The key for sound appraisal is the correct identification of the cause or causes of structural damage.

Most traditional buildings have a large factor of safety, which shields them from catastrophe or progressive collapse, so that there is time for the investigation to be thorough, the work being under no commercial pressures of time and money.

The important thing with health monitoring of old structures is that it could determine whether any strengthening of the old building is really needed. This health monitoring is particularly important in cities like Kandy, which was named as a world heritage city by UNESCO. In such cities, designers and planers are faced with problems of preserving historical buildings with the phase of development. In such circumstances, health monitoring of old structures is of paramount importance. 


\section{Theoretical background of the health monitoring of structures}

It is important to be familiar with different terms used in health monitoring. Furthermore, there should be a clear understanding of ways in which condition of structures deteriorate.

\subsection{Damage and decay}

The term damage is used to describe a situation in which a structure has lost some or all of its bearing capacity, a condition that can lead to failure and collapse. Damage is breaking away of elements, permanent deformation, out of plumbness and etc.

Decay or deterioration is an alteration of the material that usually leads to a reduction in resistance, increased brittleness, porosity and a loss of material that usually begins from the outside and work inward. It is mainly related to physical or chemical actions. Corrosion of reinforcement is a good example of decay.

\subsection{The origins of damage and decay}

The origins of damage and deterioration can be attributed to one or more of the following factors.

\subsubsection{Lack of due care in the original design}

The safety of a construction can never be an absolute certainty, since it is affected by the uncertainty of evaluation of the various phenomena and characteristics and therefore depends on probabilities. Its strength and the action to which it may be subjected may have more unfavourable values than those envisaged in its design. Safety coefficients by architects and engineers are designed to meet these uncertainties.

Thus, the probability that some event, as for example an earthquake, may have a more serious effect on a structure with regard to say damage or collapse than those envisaged in the design depends on the degree of caution used when the safety levels were established at the design stage. However, safety has a cost and even modern codes accept a certain probability.

\subsubsection{Lack of scientific knowledge}

A proper understanding of the main phenomena that increase the probability of critical situations occurring can only be acquired through scientific knowledge. In the case of ancient structures, the lack of scientific knowledge was usually compensated by practical experience and by construction of the structural components with more than adequate dimensions. When innovative structural concepts arose, such as in the case of Gothic cathedrals, numerous collapses and much damage had to occur before the builders acquired the necessary experience and arrived at a successful structural solution.

\subsubsection{Use of construction beyond their life expectancy}

Every construction is designed with a more or less consciously predetermined life expectancy. This concept is implicit in the formulation of modern codes, in which "safety coefficients" and the corresponding probability that critical situation will arise, are fixed in relation to a certain life expectancy for the structure. This may vary from decades to centuries, depending on the more or less rapid evolution of factors such as functionality, convenience, maintenance costs, etc.

Ancient buildings have often survived well beyond their life expectancies, so that damage, and especially weathering and decay, can be considered normal phenomena.

\subsubsection{Errors and imperfections in the original design}

Progress in the field of construction has been achieved more by intuition and experience than by scientific knowledge and therefore safety was ensured by repeating similar shapes and dimensions. The development of forms, shapes and proportions was based on earlier models and experiences that had proved less prone to damage and collapse, but even that route did not totally avoid all risk.

\subsubsection{Introduction of new and unknown factors}

Constructions may have been designed for conditions different from those that effectively occur. Environmental changes (speeding up the process of deterioration of materials), variations in the use of structures (increased loads, etc.), structural alterations (extensions, partial demolition, etc.), earthworks, (excavations, 
variations in water levels, embankments, Fillings, galleries) and earthquakes in areas not originally considered seismic are among the principal causes of damage and decay.

\subsection{Kinds of damage}

\subsubsection{The visible signs}

Depending on the type of material and construction, visible signs of damage can be divided into three main categories:

\subsubsection{Crack in materials not resistant to tensile stresses}

This is most frequent in masonry, which has a very low resistance to tension. In concrete structures, cracks are normally associated with insufficient reinforcement. But this is not the case in every time. It can be attributed to several other reasons as mentioned in section 2.1 and 2.2 .

\subsubsection{Permanent deformations:}

These are particularly linked to the effects of bending induced by off-centre loads and horizontal thrusts (arches and etc). Another important factor may be related to soil deformation.

\subsubsection{Cracks and cracks patterns}

Cracks are the most frequent sings of damage. The problem is thus to establish the relationship between crack patterns and the distribution of forces, possible soil deformations, earthquakes, etc.

On actual buildings the problem can be made more difficult by the presence of local weakening (cavities, cracks, etc) or strengthening (reinforcement in concrete structures and chains), which are not always visible.

In material such as masonry, which is not resistant to tension and is conceived essentially to withstand only compression, the cracks in the tensile zones are the most visible signs. Their presence, however, is not usually an indication of dangerous situations.

By increasing forces, or altering their distribution, cracks that initially represent merely the adjustment of the material to a new situation of equilibrium can spread, until, in some cases, especially when compressed areas are involved, a mechanism leading to collapse can be induced.

The zones in which the cracks first appear depend on the type of structure and materials, the presence of possible weaker or stronger zones, the distribution of the forces and finally the stresses.

To identify the direction along which the cracks will develop, the isostatic lines, being the lines along which the main stresses flow, can be considered. Cracks initially will be perpendicular to the tension isostatic lines, where the stresses exceed the strength; with increasing stress, these lines may progress in slightly different directions since the cracks themselves change the original isostatic lines.

Although the evolution of the crack patterns can only be fully identified using a step by step nonlinear procedure, because of the progressive variations in the stiffness of the structure. It is usually possible to make a qualitative evaluation of how the isostatic lines will be changed from the initial cracks.

The examination of the pattern of cracking also makes it possible to identify the kind of actions that produced them and consequently the cause of the actual damage.

\subsubsection{Crushing}

Crushing occurs when compressive stresses reach the strength of materials and is more complex than phenomena caused by tensile stresses.

As compression stresses increase, minute cracks appear mainly parallel to the direction of the stress. If there is no lateral constraint, the situation can deteriorate until transversal swelling occurs, flakes become detached and the internal nucleus of the compressed element may suddenly crumble.

Crushing phenomena are extremely dangerous on account of the fact that they often give very little warning and can have possible catastrophic consequences for a whole building if adjacent structural elements or areas are not able to compensate in someway. 
The visible signs of crushing vary according to the materials involved and may be barely detectable, or hidden and due to the small axial deformation involved can usually only be seen on the affected elements while no signs will be visible on other parts of the construction.

\subsubsection{Diagnosis}

The above sections briefly described some of the most frequent causes of damage and failure and the corresponding signs visible on structures. The designer, however, is in quite a different situation. Starting from his observation of abnormal situations, he must identify the cause or more frequently, the underlying causes.

This connection between an effect and its cause is complicated by the interaction of different events occurring at various times. All these factors can alter and influence the damage and the resulting crack patterns, making the designer's task much more difficult.

The process of identifying the causes of damage in structures and decay in materials involve the use of different procedures or criteria, based on the observation of the building.

To improve the knowledge of the structural and material characteristics and obtain more reliable data it is usually necessary to carry out specific investigations, sometimes using a monitoring system to record the changes in various phenomena, so as to better identify possible causes.

As in medicine, a correct and complete diagnosis can only be achieved if all the data and information are combined with intuition, experience and individual ability.

\section{Experimental measurements}

In most time in health monitoring, strains, displacements and acceleration are measured and electrical resistance strain gauges and displacement transducers are used for strain and displacement measurements. Where the dynamic nature of structures is to be measured, acceleration gauges are used.

The CDP-50 displacement transducer, shown in Figure 1, is a compact displacement transducer that is very easy to operate. Its large output and excellent consistency ensure high-precision

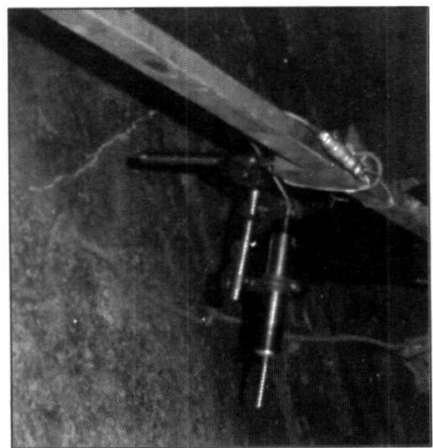

Figure 1: CDP 50 Displacement Transducer

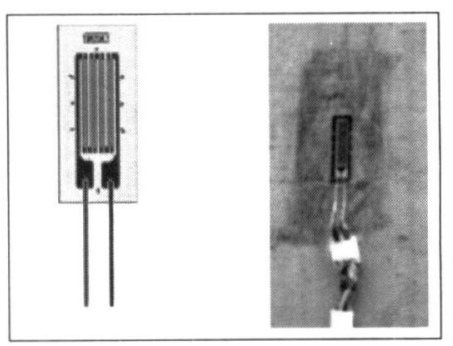

Figure 2: Electrical Resistance Strain Gauge

measurements, while it can be used for both static and dynamic measurements.

Electrical resistance strain gauges as shown in Figure 2 are devices used to measure strains in both static and dynamic load conditions. The data is acquired through TDS-303 data logger. It is a sensitive and accurate equipment used for recording displacement, strain, and acceleration measurements, and it allows automatic recording of data. Measured data are printed and recorded in the internal memory of the data logger or in a disk, which can be uploaded to the computer, via either GP-IB or RS $232 \mathrm{C}$ interface.

\section{Case Study I: Maligakanda Old Reservoir Wall}

The Maligakanda service reservoir, built about 120 years ago, has the internal dimensions of 192 $\mathrm{ft}$ in length and width while the height is $45 \mathrm{ft}$. Later, all its four sides have been inter connected with a grid of prestressed concrete beams, 16 in each direction as shown in the Figure 3. However sliding movements in the concrete walls of the reservoir were suspected, and in order to assess the structural integrity of walls, an experimental and a numerical analysis of a wall was carried out. The objective of this study was to find out whether there are significant movements in the wall due to water loading [3]. 


\subsection{Experimental set up}

It has been observed that movements of the reservoir walls occur when the reservoir is filled with water, and this usually happens from $6 \mathrm{PM}$ to $6 \mathrm{AM}$ of the next date. As displacement was the main quantity to be checked, displacement transducers were attached to the reservoir wall and displacements were measured as the reservoir was being filled and also when it was emptied.

\subsection{Finite element analysis}

To identify the best structural model that suits the behaviour of the wall a finite element analysis was carried out employing the generalpurpose package SAP2000.?Four plane strain finite element models with various types of restrains were developed as mentioned below, and the results from these finite element models were compared with field measurements. A four meter wide strip of the wall was used in the analysis. Prestressing force applied by the tendon on the wall was replaced by equivalent forces of $2900 \mathrm{kN}$ at relevant nodes of the model. The prestressed concrete beams were replaced by spring supports with a stiffness value of 293 $\mathrm{kN} / \mathrm{mm}$, which was calculated by considering both effects of concrete and steel tendons. The water pressure was applied to the inner surface of the wall taking the unit weight of water as 10 $\mathrm{kN} / \mathrm{m}^{3}$.

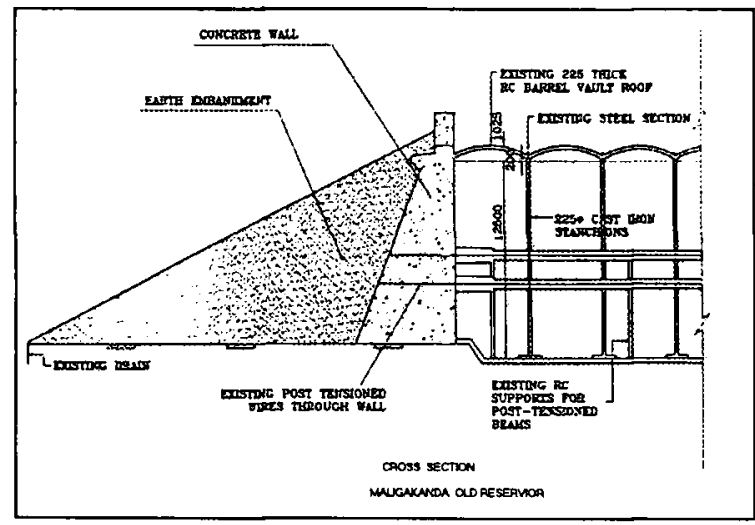

Figure 3: A view of the Maligakanda dam

Model (1) : All Three translational degrees of freedoms were restrained at the base of the wall and subjected to the water pressure at water height of $6 \mathrm{~m}$ from the bottom. (Base is laterally fixed and water height is $6 \mathrm{~m}$ )
Model (2) : Lateral translational degree of freedom is free (allow to move) and other two translational degrees of freedoms are restrained at the base of the wall and subjected to the water pressure at water height of $6 \mathrm{~m}$ from the bottom. (Base is laterally free and water height is $6 \mathrm{~m}$ )

Model (3) : All Three translational degrees of freedoms are restrained at the base of the wall and subjected to the water pressure at water height of $8.5 \mathrm{~m}$ from the bottom. (Base is laterally fixed and water height is $8.5 \mathrm{~m}$ )

Model (4) : Lateral translational degree of freedom is free (allow to move) and other two translational degrees of freedoms are restrained at the base of the wall and subjected to the water pressure at water height of $8.5 \mathrm{~m}$ from the bottom. (Base is laterally free and water height is $8.5 \mathrm{~m}$ ).

\subsection{Validation of the Finite Element Model}

Validation of model was carried by comparing the results taken from the analysis with those from field tests. Pressure loading, as the water height rises from $6.0 \mathrm{~m}$ to $8.5 \mathrm{~m}$ height was taken as the load action on the wall. For the comparison of results change of displacement were considered separately in Models (1) \& (3)(Base is laterally fixed whose lateral stiffness is infinity) and Model (2) \& (4)-(Base is laterally free whose lateral stiffness is zero). Then, these results were compared with actual field measurements.

These results suggest that the behaviour of the Wall is in between laterally base fixed and base free conditions. This means that there is a sliding at the base and this can be modelled using spring supports. Interpolating linearly the extreme cases the stiffness value was determined as $195 \mathrm{kN} /$ mm per meter length of the Wall.

\subsection{Results and conclusions}

The results show that there is good agreement among analytical results from the FE Model and measurements. Hence, it may be concluded that the FE model is validated and it can be used in other analyses involving different loading on the wall. 
From the results obtained, it was found that normally the prestressed beams take around $30 \%$ of lateral water load and the rest is taken by the soil backfill and base of gravity wall in friction. Considering reservoir empty stage as the initial position, the total sliding of base of the gravity wall is $4.90 \mathrm{~mm}$ and maximum displacement at top is $5.39 \mathrm{~mm}$.

Experimental and analytical investigations show that there is sliding at the base of the gravity wall due to water load, though the post tensioned beams are present. The walls will not be stable against sliding if the post tension beams loose their effect. Considering the above factors it could be said that the risk of failure of the reservoir cannot be easily ignored. This reveals that this old reservoir is in a structurally doubtful stage for future services.

\section{Case study II: Galle Face Hotel}

The selected structure for the health monitoring is a part of the Galle Face Hotel in Colombo. It is a steel framed structure having four storeys, constructed in the 1880's [4]. Figure 4 shows an outside view of the building.

As the building is on the seafront, heavy corrosion has taken place in structural components such as columns and beams. Recently, the building was rehabilitated with some structural repair and modifications such as welding plates at places where there is loss of material due to corrosion [5]. The objective of the study was to find out whether the original building could safely be used with these modifications.

Towards this objective, load testing of the building was carried out. Displacement transducers were fixed to flange plates of the several columns as shown in Figure 5, and strain gauges were also attached to the repaired sections as indicated in Figure 6. Displacements and strains were measured with imposed loads on floors, and were interpreted through the Data Logger TDS-303.

As per the Codes [ $6 \&$ 7], test load to be applied per floor is $1.05 \mathrm{kN} / \mathrm{m}^{2}$ and the total load applied for all four floors is $4.2 \mathrm{kN} / \mathrm{m}^{2}$. Since the interest was on the columns in the ground floor, a load of $1.5 \mathrm{kN} / \mathrm{m}^{2}$ each for first and second floors, and a load of $1.2 \mathrm{kN} / \mathrm{m}^{2}$ for the third

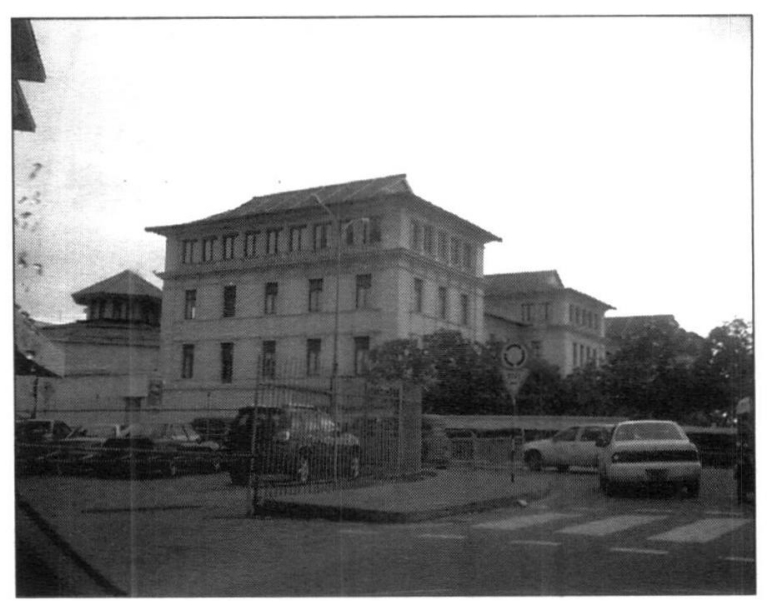

Figure 4: An outside view of the building

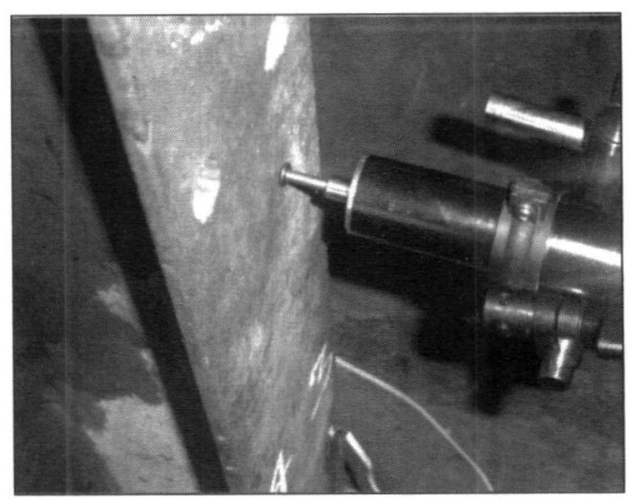

Figure 5: Displacement transducers in measuring displacement

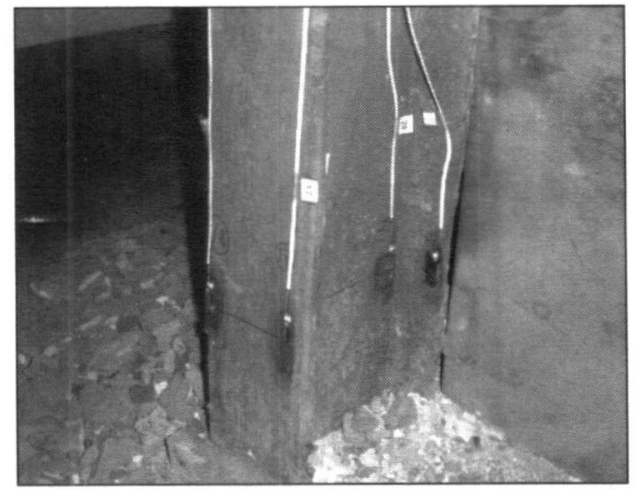

Figure 6: Strain Gauges attached to the columns of the wall

floor, were applied. This will give the same effect on the ground floor columns as the 4.2 $\mathrm{kN} / \mathrm{m}^{2}$ total load.

\subsection{Results and conclusions}

From the observed strains at some selected locations and computed stresses, it was seen that in some repaired sections of the columns, stresses are not evenly distributed. This may be due to the uneven connections and stiffness variations of the connections, giving rise to unsymmetrical bending of the connected plates 
of the repaired sections. This will give rise to bending in other parts of the column as well. Except at one location at the repaired section of a tested column, stresses found under the applied loading were low.

\section{Case Study III: Reinforced concrete deck bridge at Elhera}

The bridge (43/2) situated Naula-ElheraKalugaga (B312) road was evaluated for its current conditions. It is a reinforced concrete deck bridge with random rubble masonry abutments and it was constructed in 1979. Views of the bridge are as shown in Figures $7 \& 8$.

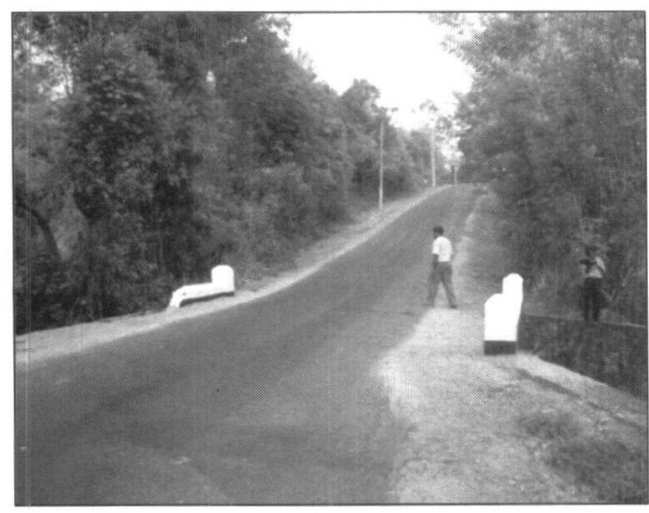

Figure 7: A View of the case study bridge (bridge Number $43 / 2$ ) in B312 route

Underneath the bridge deck, reinforcement has been exposed and corroded heavily. There is a need to estimate the current condition of the bridge over the normal traffic flow of this bridge.

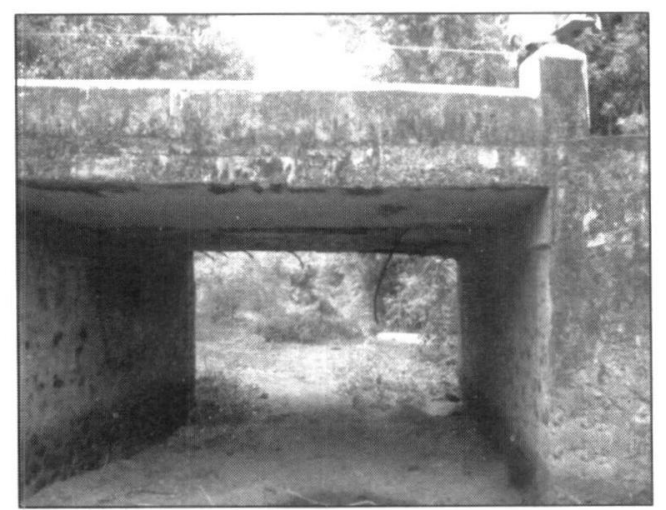

Figure 8: A side view of the case study bridge

This bridge was evaluated to check for its current serviceability conditions. Strain gauges were attached and response of the bridge was measured due to actual vehicle passage. In addition, with the experimental findings, theoretically with the use of structural reliability theory, current condition of the bridge was estimated. Table 1 shows the results of the reliability calculations [8]. From these analyses, it was found that currently the condition of the bridge is satisfactory even though corrosion has been on reinforcements.

\section{Future of health monitoring}

The future of health monitoring of structures seems to be rather optimistic as more and more innovative techniques and instruments are introduced. One such area is smart sensing. These are wireless sensors once attached to the structure, it transmits the information to central processing unit. As such, during the construction stage, these sensors can be attached to the structure and they will transmit the deterioration process and based on information, health monitoring of structures can be carried out and proper maintenance can be effected at the right time.

Table 1: Summary of the reliability calculation

\begin{tabular}{|l|l|l|}
\hline Case & $\begin{array}{l}\text { Reliability } \\
\text { index } /(\beta)\end{array}$ & $\begin{array}{l}\text { Failure } \\
\left.\text { probability/( } \mathbf{P}_{f}\right)\end{array}$ \\
\hline $\begin{array}{l}\text { Case I: COV } \\
(A) \text { required }=0\end{array}$ & 4.14 & $1.5 \times 10^{-5}$ \\
\hline $\begin{array}{l}\text { CaseII: COV } \\
(A) \text { required }=.05\end{array}$ & 3.92 & $4.4 \times 10^{-5}$ \\
\hline $\begin{array}{l}\text { CaselII: COV } \\
\text { (A) required }=0.1\end{array}$ & 3.42 & $3.1 \times 10^{-4}$ \\
\hline
\end{tabular}

\section{Conclusions}

Health monitoring of old structures involves detective work, but with the use of modern tools for experimental and analytical investigation, a satisfactory evaluation can be made. Thereby, important decisions can be made regarding their remaining service life and whether they need more maintenance to assure the safety of their occupants.

\section{Acknowledgement}

The author likes to express his sincere acknowledgement to Prof. M. P. Ranaweera, Dept. of Civil Engineering of University of Peradeniya for the valuable contributions given in the case study works. 


\section{References}

1. Atashi, M., Lachemi M. and Kianoush (2007). Numerical modeling of the behavior of overlaid slab panels for reinforced concrete bridge decks, Journal of Engineering Structures, ELSEVIER, 29 (2), pp. 271-281.

2. Kong, J.S. and Frangopol, D.M. (2004). CostReliability interaction in life-cycle cost optimization of deteriorating structures, Journal of Structural Engineering, ASCE, 130 (11), pp. 1704-1712.

3. M.P.Ranaweera and P.B.R.Dissanayake (2003), Determination of the current state of the Maligakanda old reservoir wall of National Water Supply and Drainage Board, Engineering Design Centre, University of Peradeniya, Peradeniya, Sri Lanka.

4. M.P.Ranaweera and P.B.R.Dissanayake (2003), Load Testing of column being repaired at Gall face Hotel Colombo, Engineering Design Centre, University of Peradeniya, Peradeniya, Sri Lanka.

5. P.B.R.Dissanayake and M.P.Ranaweera (2004), Condition Evaluation of Old Structures, Proc. Of Annual session of IESL Central Province Kandy, Sri Lanka.

6. BS 8110-1 Structural use of concrete Part 1: Code of practice for design and construction (1997), British Standard Institute, UK

7. ES 6399 Loading for Buildings - Part 1: Code of Practice for Dead and Imposed Loads (1984), British Standard Institute, UK.

8. P.A.K. Karunananda, Service life prediction of bridges using structural reliability theory, (M. Phil. Thesis 2004), University of Peradeniya, Sri Lanka. 